\title{
Incidence and Risk of Thyroid Dysfunction in Advanced or Metastatic Non-small Cell Lung Cancer Patients Treated with Pembrolizumab: A Meta-analysis
}

\author{
Haisam Abid ${ }^{1}$, Maryam Khavandi ${ }^{1}$, Nadir Siddiqui ${ }^{1}$, Panadeekarn Panjawatanan ${ }^{1}$, Anush Patel ${ }^{2}$ \\ 1. Internal Medicine, Bassett Medical Center, Cooperstown, USA 2. Hematology / Oncology, Bassett Medical Center, \\ Cooperstown, USA
}

Corresponding author: Haisam Abid, haisamabid123@gmail.com

\begin{abstract}
Thyroid dysfunction is one of the major side effects associated with Pembrolizumab in the treatment of advanced or metastatic non-small cell lung cancer (NSCLC). We performed a systematic review and metaanalysis of randomized clinical trials to determine its overall incidence. A literature search was conducted using the electronic database engines PubMed and Google Scholar from inception to March 2019. Eligible studies were prospective randomized clinical trials with advanced or metastatic NSCLC. The pooled incidence, risk ratio (RR), and 95\% confidence interval (CI) of thyroid dysfunction were calculated using the random-effect model. Given the possibility of a between-study variance, we used the random-effect model rather than the fixed-effect model.
\end{abstract}

A total of four studies, including 1603 patients, were selected for analysis. Among patients receiving Pembrolizumab, the overall incidence of all-grade thyroid dysfunction was 19.8\% (95\% CI: 16.6-23.3\%). Pembrolizumab was associated with a significantly increased risk of thyroid dysfunction of all grades, with a relative risk of 3.9 ( $95 \% \mathrm{CI}: 2.08-7.42 \%$, $\mathrm{p}=0.084$ ) in comparison with the controls. Therefore, there is a significant increase in developing thyroid dysfunction in advanced or metastatic NSCLC patients treated with Pembrolizumab.

Received 10/22/2019 Review began 10/23/2019 Review ended 10/24/2019 Published 10/25/2019

\section{() Copyright 2019}

Abid et al. This is an open access article distributed under the terms of the Creative Commons Attribution License CC-BY 3.0., which permits unrestricted use, distribution, and reproduction in any medium, provided the original author and source are credited.
Categories: Oncology, Pulmonology

Keywords: pembrolizumab, non-small cell lung cancer, thyroid dysfunction, incidence, risk

\section{Introduction And Background}

Lung cancer is the leading cause of cancer-related death all over the world. The use of immunotherapy has gained precedence in the treatment of malignancies. Normally, the immune system can detect and destroy an abnormal cell using lymphocytes called T-cells. The immune system has a series of checkpoints to prevent T-cells from attacking the body's own cells. Programmed cell death 1 (PD-1) is one of these checkpoints. One hallmark of cancer is immune evasion, in which the immune system does not mount an effective antitumor response because tumor cells "hijack" the pathway to hide from T-cells [1]. PD-1 is a negative co-stimulatory receptor that is primarily expressed on the surface of activated T-cells, which blocks killing a cell when it interacts with its ligand called programmed cell death ligand (PD-L1) [2-3]. Some tumors evade the immune response by expressing these ligands on their cell surface [4]. Pembrolizumab is a monoclonal antibody directed against programmed cell death-1 receptor (anti-PD-1) and is used in the adjuvant treatment of non-small cell lung cancer (NSCLC) [5]. However, as Pembrolizumab acts to block the immune system checkpoints, it can cause T-cells to attack healthy cells, causing various autoimmune diseases referred to as immune-related adverse events (irAEs). Thyroid irAEs in patients treated with Pembrolizumab are increasingly reported as one of the most common adverse effects [6]. Given the widespread use of Pembrolizumab in advanced or metastatic NSCLC and increasing reports of thyroid dysfunction in patients treated with Pembrolizumab, we have conducted a systematic review of the literature and a meta-analysis of randomized controlled trials to evaluate the incidence and relative risk of thyroid dysfunction in patients with advanced NSCLC treated with Pembrolizumab versus controls.

\section{Review}

\section{Materials and methods}

A literature search was conducted using the electronic database engine PubMed from inception to April 2019 for identifying randomized controlled trials in patients with advanced or metastatic NSCLC treated with Pembrolizumab. The combinations of keywords used were "non-small cell lung cancer" or "NSCLC" and "Pembrolizumab."

Randomized controlled trials were eligible for inclusion if they reported thyroid dysfunction with the use of 
Pembrolizumab or controls. Articles were excluded if (1) they were not written in English or (2) no outcomes were reported. Four reviewers (HA, NS, PP, and MK) independently performed study selection according to the eligibility criteria. Disagreements were resolved by discussion with a fifth reviewer (AP).

The following data were independently abstracted into a standardized form: study characteristics (study design, primary author, time period of study, year of publication), characteristics of the study population (total number of patients, mean age of patients, gender, tumor histology, smoking status, and previous radiotherapy and chemotherapy). A Preferred Reporting Items for Systematic Reviews and Meta-Analyses (PRISMA) flow diagram detailing the review process is shown in Figure 1.

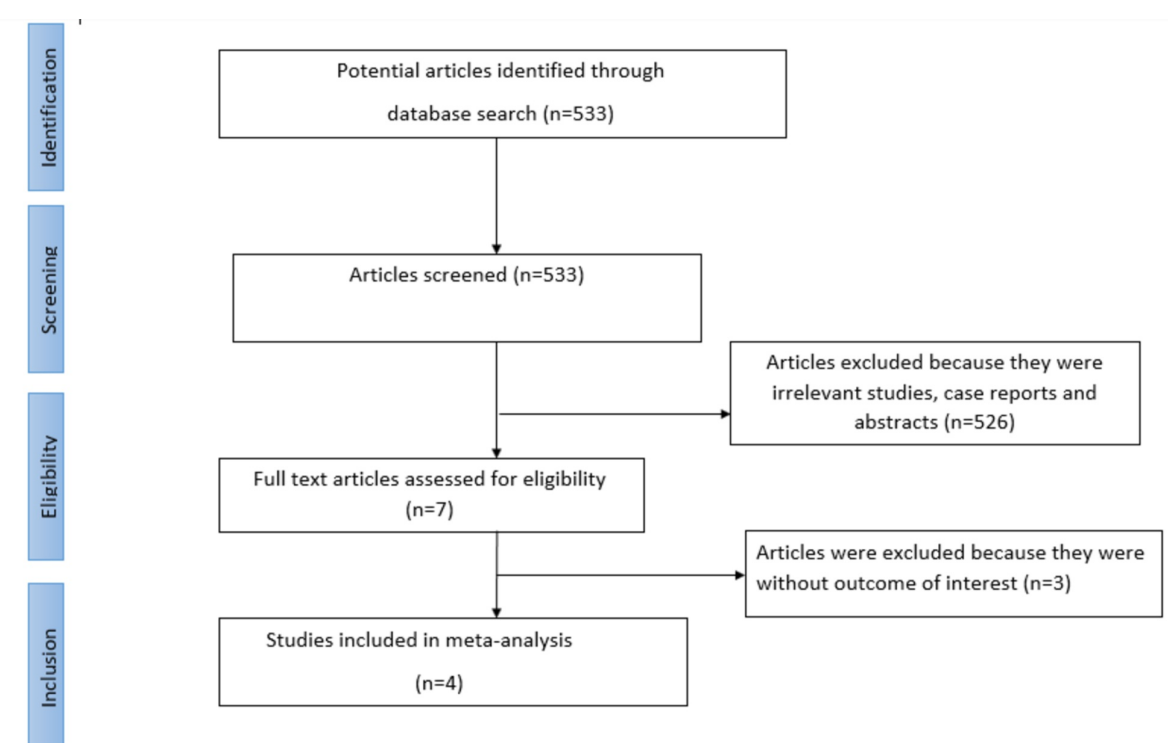

\section{FIGURE 1: Outline of our search methodology}

The primary outcome analyzed in this study was thyroid dysfunction, which was defined as an abnormality of thyroid gland functioning - either hypothyroidism or hyperthyroidism. All statistical analyses were performed using Comprehensive MetaAnalysis program software 3.0 (Biostat, Englewood, NJ). Because of the possibility of a between-study variance, we used a random-effect model rather than a fixed-effect model. Forest plots were constructed to evaluate the pooled incidence and relative risk of thyroid dysfunction in advanced or metastatic NSCLC due to Pembrolizumab versus control. To determine between-study heterogeneity, we applied Cochran's Q test and $I^{2}$ statistics. A value of $I^{2}$ of $0 \%-25 \%$ represents insignificant heterogeneity, 26\%-50\% low heterogeneity, 51\%-75\% moderate heterogeneity, and 76\%-100\% high heterogeneity [7-8].

\section{Results}

Our search yielded a total of 562 potentially eligible articles using our search strategy. After excluding review articles, Phase I studies, single-arm Phase II studies, case reports, meta-analyses, and observational studies, we selected four randomized controlled trials (reference), including three Phase III studies and one Phase II study, which fulfilled our inclusion criteria, and their characteristics are listed in Table 1 . We systematically assessed the quality of eligible studies using the published criteria [7]. The Jadad score was listed for each trial in Table 1 . 


\section{Cureus}

\begin{tabular}{|c|c|c|c|c|c|}
\hline $\begin{array}{l}\text { Study } \\
\text { included }\end{array}$ & Primary author & $\begin{array}{l}\text { Time period of } \\
\text { study }\end{array}$ & $\begin{array}{l}\text { Year of } \\
\text { publication }\end{array}$ & Study design & $\begin{array}{l}\text { Study } \\
\text { quality }\end{array}$ \\
\hline 1. & Reck et al. Keynote-024 [9] & 2014-2015 & 2016 & $\begin{array}{l}\text { Phase } 3 \text { Randomized Controlled } \\
\text { trial }\end{array}$ & $\mathrm{b}$ \\
\hline 2. & Langer et al. Keynote-021 [10] & 2014-2016 & 2016 & $\begin{array}{l}\text { Phase } 2 \text { Randomized Controlled } \\
\text { trial }\end{array}$ & 5 \\
\hline 3. & Gandhi et al. Keynote-189 [11] & 2016-2017 & 2018 & $\begin{array}{l}\text { Phase } 2 \text { Randomized Controlled } \\
\text { trial }\end{array}$ & 5 \\
\hline 4. & $\begin{array}{l}\text { Paz-Ares et al. Keynote-407 } \\
\text { [12] }\end{array}$ & 2016-2017 & 2018 & $\begin{array}{l}\text { Phase } 3 \text { Randomized Controlled } \\
\text { trial }\end{array}$ & 5 \\
\hline
\end{tabular}

\section{TABLE 1: Characteristics of studies included in the meta-analysis}

The characteristics of patients in the included studies are reported in Table 2.

\begin{tabular}{|c|c|c|c|c|c|c|c|c|c|c|c|}
\hline \multirow{3}{*}{$\begin{array}{l}\text { Study } \\
\text { name } \\
\\
\text { Keynote- } \\
024\end{array}$} & \multirow{2}{*}{$\begin{array}{l}\text { Intervention } \\
\text { Pembrolizumab }\end{array}$} & \multirow{2}{*}{$\begin{array}{l}\text { Number } \\
\text { of } \\
\text { patients } \\
\text { (n) } \\
154\end{array}$} & \multirow{2}{*}{$\begin{array}{l}\begin{array}{l}\text { Mean } \\
\text { Age } \\
\text { (years) }\end{array} \\
64.5\end{array}$} & \multirow{2}{*}{$\begin{array}{l}\text { Male } \\
\text { no. } \\
(\%)\end{array}$} & \multirow{2}{*}{$\begin{array}{l}\text { Female } \\
\text { no. (\%) } \\
62 \\
(40.3)\end{array}$} & \multirow{2}{*}{ 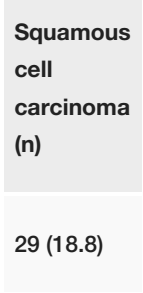 } & \multirow{2}{*}{$\begin{array}{l}\begin{array}{l}\text { Non- } \\
\text { squamous } \\
\text { cell } \\
\text { carcinoma } \\
\text { (n) }\end{array} \\
125(81.2)\end{array}$} & \multicolumn{2}{|c|}{$\begin{array}{l}\text { Smoking status } \\
\text { Smoker Non- } \\
\text { Smoker }\end{array}$} & \multirow{2}{*}{$\begin{array}{l}\text { Previous } \\
\text { Radiotherapy- } \\
\text { n (\%) } \\
\text { Not reported }\end{array}$} & \multirow{2}{*}{$\begin{array}{l}\text { Previous } \\
\text { Chemotherapy- } \\
\text { n (\%) }\end{array}$} \\
\hline & & & & & & & & $\begin{array}{l}149 \\
(96.8)\end{array}$ & $\begin{array}{l}5 \\
(3.2)\end{array}$ & & \\
\hline & Placebo & 151 & 66 & $\begin{array}{l}95 \\
(62.9)\end{array}$ & $\begin{array}{l}57 \\
(27.1)\end{array}$ & $27(17.9)$ & $124(82.1)$ & $\begin{array}{l}132 \\
(87.4)\end{array}$ & $\begin{array}{l}19 \\
(12.6)\end{array}$ & Not reported & $4(2.7)$ \\
\hline \multirow{2}{*}{$\begin{array}{l}\text { Keynote- } \\
021\end{array}$} & Pembrolizumab & 60 & 62.5 & $\begin{array}{l}22 \\
(37 \%)\end{array}$ & $\begin{array}{l}38 \\
(63 \%)\end{array}$ & $\begin{array}{l}\text { Not } \\
\text { reported }\end{array}$ & $58(97 \%)$ & $\begin{array}{l}45 \\
(75 \%)\end{array}$ & $\begin{array}{l}15 \\
(25 \%)\end{array}$ & Not reported & $4(7 \%)$ \\
\hline & Placebo & 63 & 63.2 & $\begin{array}{l}26 \\
(41 \%)\end{array}$ & $\begin{array}{l}37 \\
(59 \%)\end{array}$ & $\begin{array}{l}\text { Not } \\
\text { reported }\end{array}$ & 55 (87\%) & $54(86 \%)$ & $\begin{array}{l}9 \\
(14 \%)\end{array}$ & Not reported & $5(8 \%)$ \\
\hline \multirow{2}{*}{$\begin{array}{l}\text { Keynote- } \\
189\end{array}$} & Pembrolizumab & 410 & 65 & $\begin{array}{l}254 \\
(62)\end{array}$ & $\begin{array}{l}156 \\
(38)\end{array}$ & $\begin{array}{l}\text { Not } \\
\text { reported }\end{array}$ & 394 (96.1) & $\begin{array}{l}362 \\
(88.3)\end{array}$ & $\begin{array}{l}48 \\
(11.7)\end{array}$ & $28(6.8)$ & $30(7.3)$ \\
\hline & Placebo & 206 & 63.5 & $\begin{array}{l}109 \\
(52.9)\end{array}$ & $\begin{array}{l}97 \\
(47.1)\end{array}$ & $\begin{array}{l}\text { Not } \\
\text { reported }\end{array}$ & $198(96.1)$ & $\begin{array}{l}181 \\
(87.9)\end{array}$ & $\begin{array}{l}25 \\
(12.1)\end{array}$ & $20(9.7)$ & $20(11.7)$ \\
\hline \multirow{2}{*}{$\begin{array}{l}\text { Keynote- } \\
407\end{array}$} & Pembrolizumab & 278 & 65 & $\begin{array}{l}220 \\
(79.1)\end{array}$ & $\begin{array}{l}58 \\
(20.9)\end{array}$ & $272(97.8)$ & $6(2.2)$ & $\begin{array}{l}257 \\
(92.1)\end{array}$ & $\begin{array}{l}22 \\
(7.9)\end{array}$ & $17(6.1)$ & $5(1.8)$ \\
\hline & Placebo & 281 & 65 & $\begin{array}{l}235 \\
(83.6)\end{array}$ & $\begin{array}{l}46 \\
(16.4)\end{array}$ & 274 (97.5) & $7(2.5)$ & $\begin{array}{l}262 \\
(93.2)\end{array}$ & $\begin{array}{l}19 \\
(6.8)\end{array}$ & $22(7.8)$ & $8(2.8)$ \\
\hline
\end{tabular}

TABLE 2: Characteristics of patients in included studies in the meta-analysis

In total, we investigated data from 1603 patients. The mean age of patients ranged from 62 to 66 years. The majority of these patients were male (65.6\%) versus female (34.4\%). Reck et al. [9] and Paz-Ares et al. [12] reported patients with squamous cell carcinoma (SCC) - 66 and 546, respectively, while Gandhi et al. [11] and Langer et al. [10] did not report the total number of patients with SCC. Out of 1603 patients, 1442 (89.9\%) were smokers versus non-smokers (11.1\%). A total of 85 (0.05\%) patients received previous chemotherapy.

A total of 1603 patients with advanced or metastatic NSCLC from four randomized controlled trials received Pembrolizumab with data of all-grade thyroid dysfunction available for analysis. The incidence among these trials showed that all-grade thyroid dysfunction ranged from $10.5 \%$ to $67.7 \%$, with the lowest incidence (10.5\%) observed in Keynote-189 and the highest incidence (67.7\%) in Keynote-407. The pooled incidence of all-grade thyroid dysfunction was $19.8 \%$ (95\% CI: 16.6-23.3\%) among patients receiving Pembrolizumab 


\section{Cureus}

from all these trials (Figure 2). Meta-analysis showed that heterogeneity $\left(\mathrm{Q}=87.683, I^{2}=96.579, \mathrm{P}=0.000\right)$ exists among these trials.

\section{Incidence of thyroid dysfunction}

\begin{tabular}{|c|c|c|c|c|c|c|c|c|c|c|}
\hline \multirow[t]{2}{*}{ Study name } & \multicolumn{5}{|c|}{ Statistics for each study } & \multicolumn{5}{|c|}{ Event rate and $95 \% \mathrm{Cl}$} \\
\hline & $\begin{array}{l}\text { Event } \\
\text { rate }\end{array}$ & $\begin{array}{l}\text { Lower } \\
\text { limit }\end{array}$ & $\begin{array}{c}\text { Upper } \\
\text { limit }\end{array}$ & Z-Value & p-Value & & & & & \\
\hline Keynote-021 & 0.233 & 0.143 & 0.356 & -3.897 & 0.000 & & & & - & $\mid$ \\
\hline Keynote-024 & 0.169 & 0.118 & 0.236 & -7.410 & 0.000 & & & & & \\
\hline Keynote-189 & 0.105 & 0.079 & 0.138 & -13.302 & 0.000 & & & & & \\
\hline \multirow[t]{4}{*}{ Keynote-407 } & 0.677 & 0.555 & 0.779 & 2.789 & 0.005 & & & & $\dashv$ & \\
\hline & 0.198 & 0.166 & 0.233 & -12.928 & 0.000 & & & & & \\
\hline & & & & & & -1.00 & -0.50 & 0.00 & 0.50 & 1.00 \\
\hline & & & & & & & Control & & mbrolizuma & \\
\hline
\end{tabular}

Heterogeneity: $Q=87.683$, l-squared $=96.579, P=0.000$

FIGURE 2: Annotated forest plot for meta-analysis of the incidence of thyroid dysfunction in advanced or metastatic non-small cell cancer patients who received Pembrolizumab.

A diamond data marker represents the overall rate from each included study (square data marker) and $95 \%$ confidence interval.

We also calculated the relative risk (RR) of thyroid dysfunction in patients with advanced or metastatic NSCLC receiving Pembrolizumab versus control. Results showed RR was 3.93 (95\% CI: 2.08-7.42, P < 0.001 ) for all-grade thyroid dysfunction (Figure 3). Thus, Pembrolizumab is associated with a significantly increased risk of thyroid dysfunction in patients with advanced or metastatic NSCLC.

\section{Risk of thyroid dysfunction}

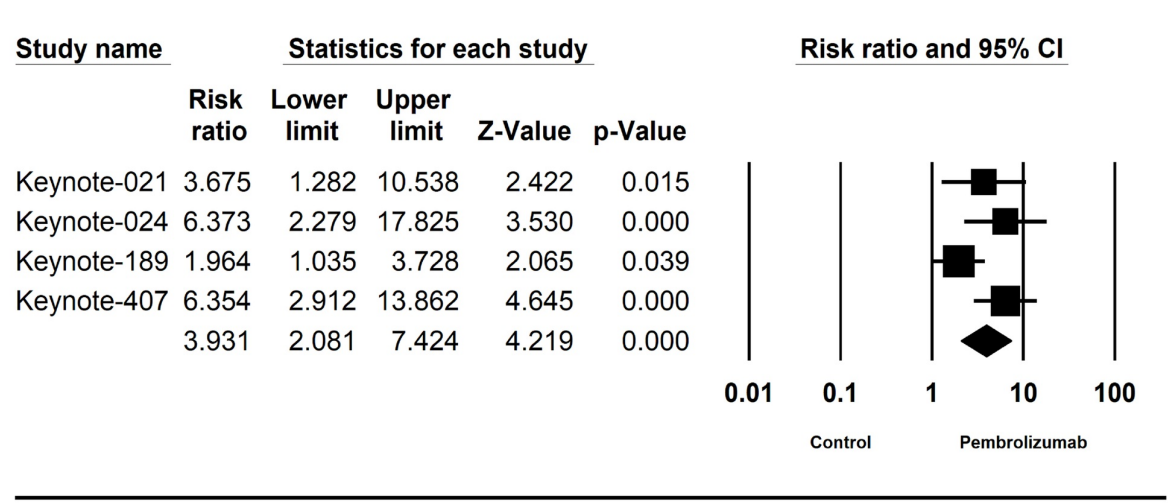

Heterogeneity test: $Q=6.658, \mathrm{l}$-squared $=54.944, P=0.08$

FIGURE 3: Relative risk of thyroid dysfunction associated with Pembrolizumab versus control.

The summary relative risks (RR) of thyroid dysfunction were calculated using the random-effects model. RR and $95 \%$ confidence intervals for each study and the final combined result are displayed numerically on the left and graphically as a forest plot on the right.

\section{Discussion}


In this systematic review, we have determined the overall risk of thyroid dysfunction associated with the use of Pembrolizumab with advanced or metastatic NSCLC cancer. We have demonstrated a high incidence of thyroid dysfunction 19.8\% (95\% CI: 16.6-23.3\% associated with Pembrolizumab. In addition, the risk of thyroid dysfunction in comparison with controls is 3.93 (95\% CI: 2.08-7.42, P < 0.001). Adequate monitoring and aggressive management of thyroid dysfunction is essential for many of these patients, as it can be lifethreatening. With the widespread use of Pembrolizumab in NSCLC patients, early recognition and effective management become more important.

Hypophysitis and thyroid disorders are the most common endocrinopathies associated with immune checkpoint inhibitors [13-15]. Hypophysitis is more commonly associated with cytotoxic T-lymphocyteassociated protein 4 (CTLA-4) inhibitors, such as ipilimumab, whereas thyroid disorders are more common in patients receiving antibodies against programmed cell death-1 receptor (anti-PD-1) such as Pembrolizumab and Nivolumab [16].

Hypothyroidism and thyrotoxicosis due to the inappropriate activation of T-cells leading to the destruction of the thyroid gland are the most frequent clinical presentations. The risk of developing thyroid dysfunction is high within the first few weeks after starting Pembrolizumab. The time frame for the development of thyrotoxicosis progressing to hypothyroidism is usually brief, often following the first Pembrolizumab dosing. High-grade thyroid dysfunction is very rare with Pembrolizumab [17].

Pembrolizumab-induced thyroid dysfunction can present in many different ways. Usually, it presents as hypothyroidism due to the autoimmune destruction of the thyroid gland. Sometimes, it can also manifest as hyperthyroidism or transient hyperthyroidism followed by longstanding hypothyroidism. Most commonly, the clinical presentation is non-specific such as fatigue or generalized weakness, which is why clinicians should have a high degree of suspicion for an accurate diagnosis. There is no antibody to diagnose Pembrolizumab-associated thyroid dysfunction. Since the clinical presentation is similar, we should distinguish primary hypothyroidism from secondary hypothyroidism due to hypophysitis because of the difference in their management. It has been recommended to obtain baseline thyroid-stimulating hormone (TSH) level prior to initiating Pembrolizumab [18].

The treatment of thyroid dysfunction depends upon the severity and presence or absence of symptoms [19]. In patients with mild disease and absence of symptoms, no treatment is indicated, and they can safely continue Pembrolizumab but close monitoring of thyroid function tests (TFTs) is recommended. For patients with mild symptoms of hypothyroidism or in asymptomatic patients with TSH levels that persist > $10 \mathrm{mIU} / \mathrm{L}$ (measured four weeks apart), the treatment of choice is levothyroxine and the close monitoring of TFTs, and the recommendation is to hold Pembrolizumab until symptoms resolve. While for mild hyperthyroidism, the treatment of choice is a beta-blocker and to hold Pembrolizumab until symptoms return to baseline. For severe cases, such as a thyroid storm, hospitalization, intravenous (IV) steroids (1-2 $\mathrm{mg} / \mathrm{kg} /$ day), and endocrinologist consultation are recommended [20]. According to Brahmer et al., Pembrolizumab can be resumed after the patient is stabilized with appropriate therapy even in severe cases [19].

The following limitations of our systematic review are worth mentioning. Despite performing a comprehensive literature search, we cannot exclude the possibility of having missed a relevant article. There are statistical heterogeneities in our meta-analysis, which may have affected the incidence of thyroid dysfunction in this population.

\section{Conclusions}

Pembrolizumab is associated with a significantly increased risk of thyroid dysfunction in patients with advanced or metastatic NSCLC as compared to controls.

\section{Additional Information}

\section{Disclosures}

Conflicts of interest: In compliance with the ICMJE uniform disclosure form, all authors declare the following: Payment/services info: All authors have declared that no financial support was received from any organization for the submitted work. Financial relationships: All authors have declared that they have no financial relationships at present or within the previous three years with any organizations that might have an interest in the submitted work. Other relationships: All authors have declared that there are no other relationships or activities that could appear to have influenced the submitted work.

\section{References}

1. Garon EB, Rizvi NA, Hui R, et al.: Pembrolizumab for the treatment of non-small-cell lung cancer . N Engl J Med. 2015, 372:2018-2028. 10.1056/NEJMoa1501824

2. Keir ME, Butte MJ, Freeman GJ, Sharpe AH: PD-1 and its ligands in tolerance and immunity. Annu Rev Immunol. 2008, 26:677-704. 10.1146/annurev.immunol.26.021607.090331

3. Freeman GJ, Long AJ, Iwai Y, et al.: Engagement of the PD-1 immunoinhibitory receptor by a novel B7 
family member leads to negative regulation of lymphocyte activation. J Exp Med. 2000, 192:1027-1034. 10.1084/jem.192.7.1027

4. Dong H, Chen L: B7-H1 pathway and its role in the evasion of tumor immunity. J Mol Med (Berl). 2003, 81:281-287. 10.1007/s00109-003-0430-2

5. Gong J, Chehrazi-Raffle A, Reddi S, Salgia R: Development of PD-1 and PD-L1 inhibitors as a form of cancer immunotherapy: a comprehensive review of registration trials and future considerations. J Immunother Cancer. 2018, 6:8. 10.1186/s40425-018-0316-z

6. Delivanis DA, Gustafson MP, Bornschlegl S, et al.: Pembrolizumab-induced thyroiditis: comprehensive clinical review and insights into underlying involved mechanisms. Int J Clin Endocrinol Metab. 2017, 102:2770-2780. 10.1210/jc.2017-00448

7. Moher D, Liberati A, Tetzlaff J, Altman DG, The Prisma Group: Preferred reporting items for systematic reviews and meta-analyses: the PRISMA statement. Int J Surg. 2010, 8:336-341. 10.1016/j.ijsu.2010.02.007

8. Higgins JP, Thompson SG, Deeks JJ, Altman DG: Measuring inconsistency in meta-analyses. BMJ. 2003, 327:557-560. 10.1136/bmj.327.7414.557

9. Reck M, Rodríguez-Abreu D, Robinson AG, et al.: Pembrolizumab versus chemotherapy for PD-L1-positive non-small-cell lung cancer. N Engl J Med. 2016, 375:1823-1833. 10.1056/NEJMoa1606774

10. Langer CJ, Gadgeel SM, Borghaei H, et al.: Carboplatin and pemetrexed with or without pembrolizumab for advanced, non-squamous non-small-cell lung cancer: a randomised, phase 2 cohort of the open-label KEYNOTE-021 study. Lancet Oncol. 2016, 17:1497-1508. 10.1016/S1470-2045(16)30498-3

11. Gandhi L, Rodríguez-Abreu D, Gadgeel S, et al.: Pembrolizumab plus chemotherapy in metastatic nonsmall-cell lung cancer. N Engl J Med. 2018, 378:2078-2092. 10.1056/NEJMoa1801005

12. Paz-Ares LG, Luft A, Tafreshi A, et al.: Phase 3 study of carboplatin-paclitaxel/nab-paclitaxel (chemo) with or without pembrolizumab (pembro) for patients (Pts) with metastatic squamous (Sq) non-small cell lung cancer (NSCLC). N Engl J Med. 2018, 105:105.

13. Min L, Hodi FS, Giobbie-Hurder A, et al.: Systemic high-dose corticosteroid treatment does not improve the outcome of ipilimumab-related hypophysitis: a retrospective cohort study. Clin Cancer Res. 2015, 21:749755. 10.1158/1078-0432.CCR-14-2353

14. Faje A: Immunotherapy and hypophysitis: clinical presentation, treatment, and biologic insights . Pituitary. 2016, 1:82-92. 10.1007/s11102-015-0671-4

15. Ryder M, Callahan M, Postow MA, Wolchok J, Fagin JA: Endocrine-related adverse events following ipilimumab in patients with advanced melanoma: a comprehensive retrospective review from a single institution. Endocr Relat Cancer. 2014, 21:371-381. 10.1530/ERC-13-0499

16. Lee H, Hodi FS, Giobbie-Hurder A, et al.: Characterization of thyroid disorders in patients receiving immune checkpoint inhibition therapy. Cancer Immunol Res. 2017, 5:1133-1140. 10.1158/2326-6066.CIR-17-0208

17. de Filette J, Jansen Y, Schreuer M, Everaert H, Velkeniers B, Neyns B, Bravenboer B: Incidence of thyroidrelated adverse events in melanoma patients treated with pembrolizumab. Int J Clin Endocrinol Metab. 2016, 101:4431-4439. 10.1210/jc.2016-2300

18. Sullivan RJ, Flaherty KT: Immunotherapy: Anti-PD-1 therapies-a new first-line option in advanced melanoma. Nat Rev Clin Oncol. 2015, 11:625-626. 10.1038/nrclinonc.2015.170

19. Brahmer JR, Lacchetti C, Schneider BJ, et al.: Management of immune-related adverse events in patients treated with immune checkpoint inhibitor therapy: American Society of Clinical Oncology Clinical Practice Guideline. J Clin Oncol. 2018, 36:1714-1768. 10.1200/JCO.2017.77.6385

20. Spain L, Diem S, Larkin J: Management of toxicities of immune checkpoint inhibitors . Cancer Treat Rev. 2016, 44:51-60. 10.1016/j.ctrv.2016.02.001 